\title{
ELECTIVE VS NON-ELECTIVE RADIAL ARTERY GRAFTS: COMPARING MIDTERM RESULTS THROUGH 64-SLICE COMPUTED TOMOGRAPHY
}

\author{
Roberto Rocha-e-Silva, Tiago S.G. Santos, Carlos E. Rochite, José A. Rocha- \\ Filho, Antônio P. Mansur, José Fabri Jr., Rogério B. Ramos, Luis A.O. Dallan, \\ Noedir A.G. Stolf
}

Rocha-e-Silva R, S.G. Santos T, Rochite CE, Rocha-Filho JA, Mansur AP, Fabri Jr. J, Ramos RB, Dallan LAO, Stolf NAG. Elective vs non-elective radial artery grafts: comparing midterm results through 64-Slice Computed Tomography. Clinics. 2007; 62(6):725-30.

BACKGROUND: Left internal thoracic artery to left anterior descending artery (LITA-LADA) grafting has become a fundamental part of the coronary artery bypass graft procedure $(\mathrm{CABG})$. This grafting in turn has led to an increased use of other arterial conduits, of which the radial artery (RA) is most popular. Whether RA grafting can be used in the emergency patient is controversial. METHODS: 47 patients with critical stenosis $(\geq 70 \%)$ in all target vessels underwent CABG with LITA and RA grafts from 1996 to 2003. Patients were divided into elective (23 patients) and non-elective groups (24 patients) with LITA and RA grafts per patient being similar in both groups. Of these 47 patients, 5 died from non-cardiac complications and 12 were unavailable. Thus, 30 patients (71\% of survivors) were studied by multidetector computed tomography. A total of 36 LITA and 64 RA grafts were studied. RESULTS: The RA patency rate for elective and non-elective grafts were $82 \%(31 / 38)$ and $85 \%(22 / 26)$, respectively $(\mathrm{p}=0.75)$. The RA had a similar patency rate for all target vessels ranging from $73 \%$ to $100 \%$. Only one patient had a redo CABG and $29(97 \%)$ are free from angina or re-intervention. LITA-LADA had a $92 \%(11 / 12)$ and $100 \%(10 / 10)$ patency rate for elective and non-elective groups, respectively $(\mathrm{p}=0.37)$. The sequential LITA-diagonal-LADA in the elective group had a 50\% $(03 / 06)$ patency rate, which was significantly lower than the $100 \%(08 / 08)$ patency rate of the non-elective group $(\mathrm{p}=0.02)$.

CONCLUSION: Radial Artery grafts can be used in both elective and non-elective patients with excellent results.

KEYWORDS: CABG. Arterial grafts. Computed tomography (CAT scan). Surgery. Emergency. Coronary artery imaging. Ischemic heart disease.

\section{INTRODUCTION.}

The Left Internal Thoracic Artery (LITA) is the conduit of choice in coronary artery bypass grafting $(\mathrm{CABG})$ because of its superior graft patency, reduced cardiac events, and enhanced short and long-term survival. ${ }^{1}$ In the search for other conduits for total arterial revascularization, $\mathrm{Acar}^{2}$ re-introduced the Radial Artery (RA) graft after a long-term observation of patent RA conduits that were thought to have

Heart Institute (InCor-HCFMUSP), University of Sao Paulo Medical School Email: rors@terra.com.br

Received for publication on July 27, 2007

Accepted for publication on September 07, 2007 been occluded in the early postoperative period.

Other studies ${ }^{3-12}$ demonstrated RA patency rates ranged from $51 \%$ to $98 \%$ up to 5 years after surgery, indicating a lack of consensus in the literature. Thus, Legare ${ }^{13}$ reported enhanced morbidity with complete arterial revascularization compared to conventional use of saphenous vein conduits, but without any difference in mortality. In contrast, Tatoulis ${ }^{14}$ claimed that higher levels of RA patency rates were associated with more severe coronary stenosis; they also reported variable patency as a function of the grafted target coronary. Their 1 and 4 year patency rates were $96 \%$ and $89 \%$, respectively. Gaudino ${ }^{15}$ demonstrated that the main determinant of a higher RA patency rate is the level of coronary ste- 
nosis and Zacharias ${ }^{16}$ showed that the use of RA as a second conduit associated with LITA-LADA compared to saphenous veins decreases long-term mortality.

There are few papers on the active use of arterial conduits in emergency CABG, but reported outcomes are good. ${ }^{17-19}$ Hayashi ${ }^{20}$ described complete arterial revascularization in 9 emergency patients with a good outcome. In a similar study, Nishida $^{21}$ conducted a study with 37 patients and showed a 5 year survival rate of $97.1 \%$ and a patency rate of $100 \%$ for RA, 3 to 4 weeks after surgery.

We have previously reported the immediate follow-up study on complete arterial revascularization with left internal thoracic artery and RA in elective versus emergency surgery to have similar clinical outcomes for both groups. ${ }^{22}$

\section{OBJETIVE}

The main objective of this study is to compare the midterm follow-up between elective and non-elective radial artery bypass grafts with 64-Slice Multidetector Computed Tomography (MDCT) in patients that had complete arterial revascularization with left internal thoracic artery and radial artery.

\section{METHODS}

The selection of patients was retrospective. All patients with critical stenosis $(\geq 70 \%)$ in all target vessels whose surgeries were performed from 1996 to 2003 by the same surgeon, had complete arterial revascularization, and was obtained with LITA and RA (without any other type of graft) were selected. Forty-seven patients underwent elective or emergency CABG.

Patients were divided into two groups, an elective group with 23 patients (17 males) and a non-elective group with 24 patients (22 males). The main pre-operative characteristics of both groups were similar and are summarized in table 1 . Most of the patients were men (37/47), between 50 and 60 years, and had triple-vessel coronary artery disease (38/47). Patients in the non-elective group had operations for unstable angina or hemodynamic instability. In the emergency group, 11 patients (46\%) underwent CABG up to 21 days after an acute myocardial infarction (AMI). There was no pre-operative use of an intra-aortic balloon pump (IAB). Two patients in the elective group and one in the non-elective group had left ventricular aneurysms that were corrected with aneurysmectomy.

The surgical approach was through sternotomy with cardiopulmonary bypass (CPB). After March 2003, the offpump surgery was performed in 4 out of 7 elective cases (57\%) and in 7 out of 12 non-elective cases (58\%). RA was
Table 1 - Pre-operative characteristics of patients in this study

\begin{tabular}{lccc}
\hline & elective & non-elective & p-value \\
\hline Sex (male/female) & $17 / 6$ & $22 / 2$ & $0.14^{*}$ \\
Age & & & \\
Mean & $60.3 \pm 8.3$ & $59.8 \pm 9.7$ & \\
Range & $43 \mathrm{a} 75$ & $37 \mathrm{a} 76$ & $0.83^{*}$ \\
Diabetes mellitus & $8 / 23$ & $8 / 24$ & $1.0^{*}$ \\
Systemic arterial hypertension & $14 / 23$ & $16 / 24$ & $0.8^{*}$ \\
Dislipidemia & $12 / 23$ & $12 / 24$ & $1.0^{*}$ \\
Smoking & $12 / 23$ & $13 / 24$ & $1.0^{*}$ \\
Tri-arterial coronary disease & $20 / 23$ & $18 / 24$ & $0.46^{*}$ \\
\hline
\end{tabular}

* Fisher's exact test; **ANOVA

harvested with a no-touch technique and with no mechanical expansion before implantation. After harvesting, the graft was left "in situ" with topic papaverine until the initialization of coronary grafting. LITA was harvested in all but one case (a re-operation with patent LITA-LADA graft). RA was grafted to all target vessels, but was grafted to the LADA in one patient. In this case, LITA was grafted to the RA, which in turn was grafted as an arch passing through the distal LADA, proximal LADA, and Diagonal and Marginal branches. LITA was grafted to LADA and, when needed and possible, to the Diagonal branch. Each distal anastomosis was considered an independent graft. RA proximal anastomoses were done in a "Y" shape with LITA except when LITA was subjectively evaluated to have a small caliber. The mean number of RA grafts per patient in the elective and non-elective groups were 2.26 and 2.08, respectively $(\mathrm{p}=0.48)$. The mean number of LITA grafts per patient in the elective and non-elective groups were 1.17 and 1.38 , respectively $(\mathrm{p}=0.17)$. This group is fully described elsewhere (22) and the main operative and post-operative characteristics of both groups are summarized in table 2 . Of these 47 patients, 5 died from non-cardiac complications and 12 were unavailable at the time of writing (one patient described himself as asymptomatic, but could not afford the time to travel from his home town to the study center; 11 patients were not found). Consequently, 30 patients ( $71 \%$ of survivors) were studied by MDCT.

This study was approved by our institution's scientific and ethical committees and all participating patients gave written informed consent.

\section{Scanning protocol}

Patients were given intravenous metoprolol (5-15mg) if their heart rate exceeded 65 beats/min, 5 minutes before the scan. No pre-treatment with nitrate was administered. MDCT was performed using a 64-slice computed tomography scanner (Aquilion 64, Toshiba Inc., Japan) with a 64 x $0.5 \mathrm{~mm}$ collimation, gantry rotation time of $400 \mathrm{~ms}$, tube 
Table 2 - Operative and post-operative characteristics of studied patients

\begin{tabular}{lccc}
\hline & elective & non-elective & p-value \\
\hline CPB time (min) & $112 \pm 27$ & $111 \pm 30$ & $0.93^{* *}$ \\
Duration of ischemia (min) & $54 \pm 14$ & $61 \pm 27$ & $0.30^{* *}$ \\
Grafts/patient & $3.43 \pm 0.79$ & $3.46 \pm 1.02$ & $0.93^{* *}$ \\
LITA grafts/patient & $1.17 \pm 0.49$ & $1.38 \pm 0.49$ & $0.17 * *$ \\
RA grafts/patient & $2.26 \pm 0.75$ & $2.08 \pm 0.93$ & $0.48^{* *}$ \\
Days under vasoactive drugs & $1.0 \pm 0.9$ & $1.2 \pm 1.0$ & $0.58^{* *}$ \\
Days in ICU & $2.4 \pm 0.9$ & $2.8 \pm 2.0$ & $0.45^{* *}$ \\
Days in Hospital & $8.1 \pm 2.5$ & $12.8 \pm 12.2$ & $0.10^{* *}$ \\
Post-operative AMI & $1 / 23$ & $5 / 24$ & $0.18^{*}$ \\
Bleeding (24 hours) & $699 \pm 332$ & $755 \pm 576$ & $0.73^{* *}$ \\
Reoperations & $0 / 23$ & $1 / 24$ & $1.0^{*}$ \\
Atrial arrhythmia & $3 / 23$ & $2 / 24$ & $0.67^{*}$ \\
Pulmonary Thromboembolism & $0 / 23$ & $1 / 24$ & $1.0^{*}$ \\
Pneumonia & $0 / 23$ & $2 / 24$ & $0.49^{*}$ \\
Neurological complications (no sequelae) & $1 / 23$ & $2 / 24$ & $1.0^{*}$ \\
Mediastinitis & $0 / 23$ & $1 / 24$ & $1.0^{*}$ \\
\hline
\end{tabular}

Fisher's exact test; **ANOVA

voltage of $120 \mathrm{kV}$, and tube current of 400 to $500 \mathrm{~mA}$, according to the patient's body mass index. Patients received a single bolus of $90-135 \mathrm{ml}$ of Iopamidol (Iopamiron $370 \mathrm{mg}$ / $\mathrm{ml}$, Bracco Diagnostics, Milan, Italy) at 4.5 to $5.0 \mathrm{ml} / \mathrm{s}$ followed by $30 \mathrm{ml}$ of saline at the same rate to reduce hyper attenuation in the superior vena cava and right heart. EKGgated images were retrospectively acquired by the fluoroscopic-tracking technique, starting automatically as soon as the signal intensity in the descending aorta reached a threshold of $120 \mathrm{HU}$ above baseline measurement.

\section{Image reconstruction and analysis}

Images were reconstructed at $75 \%$ of the heart cycle with a slice thickness of $0.5 \mathrm{~mm}$ and interval between slices of $0.3 \mathrm{~mm}$. Image analysis was performed by an experienced observer, blinded to the group allocation, using volume rendering, multiplanar reconstruction, and dedicated software tools (Vitrea 3.8, Vital Images Inc., Minnesota, USA). Grafts were analyzed based on anastomosis visualization. Anastomosis was considered patent when a clear connection between the graft and the native artery was identified in more than one view and distal filling of the native artery could be visualized. All anastomoses were evaluable by MDCT (figures 1 and 2).

\section{Statistical analysis}

Continuous variables were expressed as mean values and nominal variables as counts and percentages. Comparison between groups was performed using 2-tailed Fisher's exact test or Chi-square test for multiple groups. A p-value $<0.05$ was considered statistically significant.

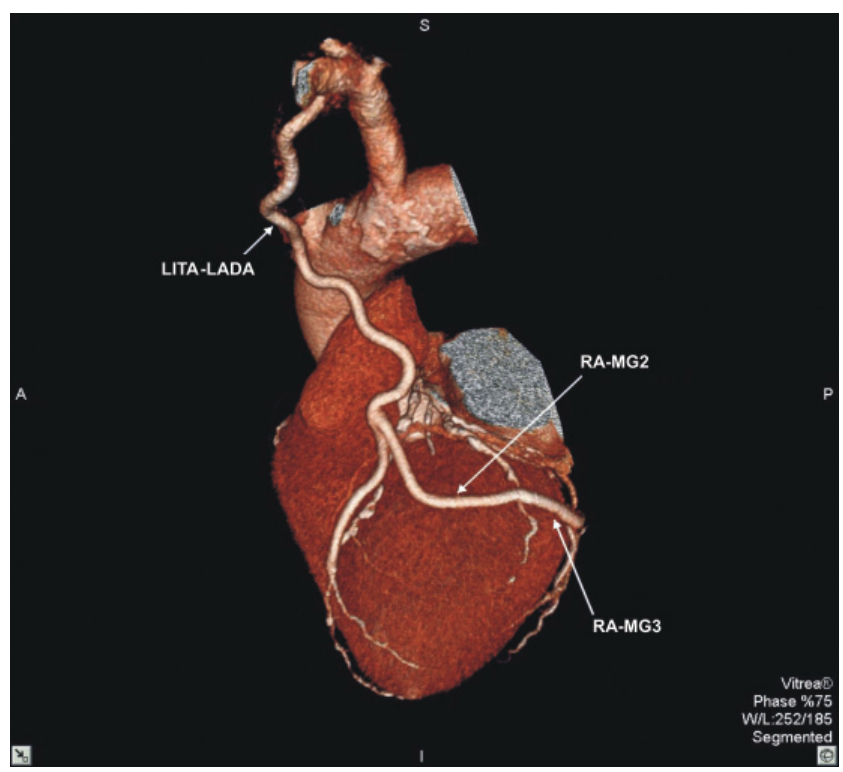

Figure 1 - Three dimensional computed tomography image for Left Internal Thoracic Artery to Left Anterior Descending Artery (LITA - LADA) and Radial Artery to marginal branches 2 and 3 (RA - MG2; RA - MG3).

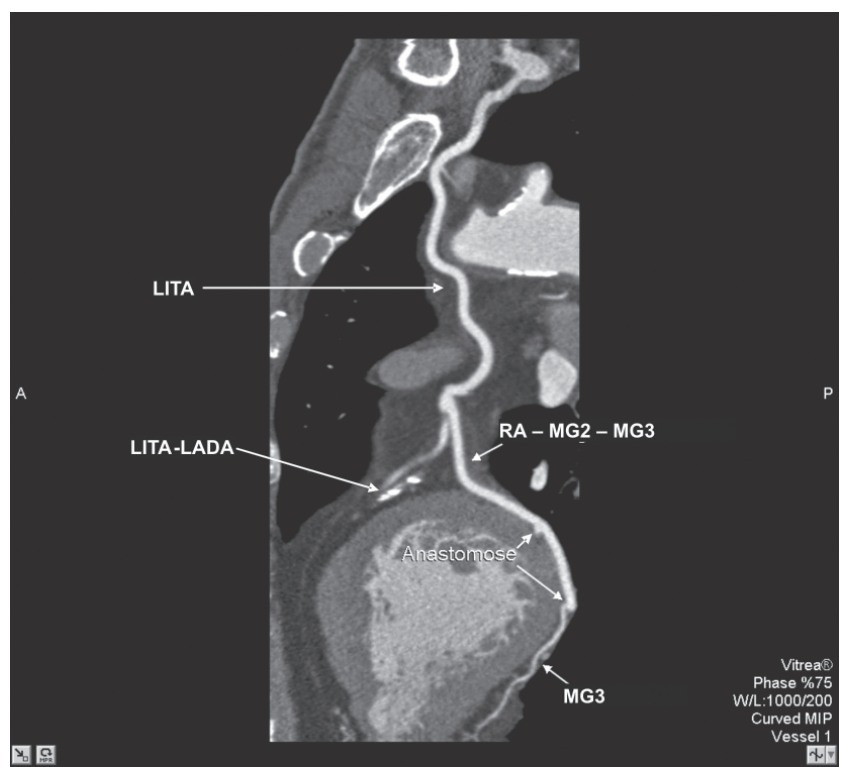

Figure 2 - Two dimensional computed tomography image for Left Internal Thoracic Artery (LITA) to Left Anterior Descending Artery (LITA - LADA) and Radial Artery to marginal branches 2 and 3 (RA - MG2 - MG3). "Anastomose" arrows indicate the respective anastomosis points

\section{RESULTS}

MDCT was performed without complications $51.7 \pm 19.8$ months after surgery. In the elective group (16 patients) and a total of 38 RA and 18 LITA grafts were studied. In the non-elective group (14 patients), 26 RA and 18 LITA grafts were studied.

The RA patency rate for elective and non-elective grafts 
were $82 \%(31 / 38)$ and $85 \%(22 / 26)$, respectively ( $\mathrm{p}=0.75)$. The overall patency rate for RA with sequential anastomosis was $84 \%$ (47/56) and without sequential anastomosis (graft for only one native vessel) was 75\% (6/8) $(\mathrm{p}=0.54)$. The RA had a similar patency rate for all target vessels ranging from $73 \%$ to $100 \%$ (table 3 ). The global patency rate for RA was $83 \%$ (53/64).

Table 3 - Radial Artery graft patency versus target vessel.

\begin{tabular}{lcc}
\hline TARGET VESSEL & PATENCY & p-value \\
\hline LADA & $2 / 2(100 \%)$ & NS \\
DIAGONAL BRANCHES & $13 / 15(87 \%)$ & NS \\
MARGINAL BRANCHES & $22 / 30(73 \%)$ & NS \\
RIGHT CORONARY AND BRACHES & $15 / 17(88 \%)$ & NS \\
\hline
\end{tabular}

NS: Chi-square test with no significant difference. LADA: left anterior descending artery.Figure 1 - Three dimensional computed tomography image for Left Internal Thoracic Artery to Left Anterior Descending Artery (LITA - LADA) and Radial Artery to marginal branches 2 and 3 (RA MG2; RA - MG3).

The overall LITA-LADA gold standard procedure (without sequential anastomosis to the Diagonal branch) had a 95\% (21/22) patency rate. LITA-LADA had a 92\% (11/12) and $100 \%(10 / 10)$ patency rate for elective and non-elective groups, respectively ( $\mathrm{p}=0.37$ ).

When LITA passed through the Diagonal branch, it had an overall patency rate of $79 \%$ (11/14), which was smaller then the LIDA-LADA rate (95\%), but nonetheless was not significant $(\mathrm{p}=0.12)$. The sequential LITA-diagonal-LADA in the elective group had a 50\% (03/06) patency rate, which was significantly lower than the $100 \%(08 / 08)$ patency rate of the non-elective group $(\mathrm{p}=0.02)$.

\section{Clinical outcome}

Patients without graft obstructions had no cardiac complications and are free from angina. Three patients have LITA obstruction, but are free from symptoms. Out of 7 patients with RA obstructions, two had angina: one was submitted to a redo CABG and one had a documented right coronary spasm (native vessel without graft) that was successfully treated with Diltiazen. Thus, out of the 30 patients, only one patient had a redo CABG and $29(97 \%)$ are free from angina or re-intervention.

\section{DISCUSSION}

The superiority of LITA as a graft for CABG is beyond dispute, but there is controversy over the kind of graft that should be associated with LITA, especially in non-elective scenarios.
This study demonstrated excellent midterm patency rates for RA, both in the elective and the non-elective scenarios. Tatoulis ${ }^{14}$ reported higher levels of RA patency rates associated with more severe coronary stenosis. Because both groups in our study had critical stenosis $(\geq 70 \%)$ in all target vessels, we expected our findings to have similar RA graft patency rates in elective and non-elective groups.

Miana compared RA and right internal thoracic artery (RITA) as a second graft, demonstrating similar immediate results, but with a longer operative time in the RITA group. ${ }^{23}$ In our study, there was no time measurement for RA harvesting, but it was always harvested simultaneously with the sternum opening; it was always ready before the LITA harvesting was finished, thus wasting no time, which can be important in the non-elective scenario. It is to be expected that non-elective patients would require higher doses of inotropic drugs during the post-operative period. This could lead to RA spasm and consequent graft failure. However, in this study, RA was harvested with a no-touch technique and with no mechanical expansion before implantation, which probably protected the endothelium and avoided spasms and posterior graft failure. There is no consensus in literature ${ }^{14-15}$ if the location of the target vessel has an impact on RA patency rate. Our study had similar excellent patency rates for all target vessels. The use of RA sequential anastomosis has the same patency rates as the single vessel graft, but it can provide complete arterial revascularization with fewer grafts and therefore reduces harvesting time and the number of proximal anastomoses. Moreover, this will shorten total surgical time.

Patients included in this report had excellent midterm graft patency rates using exclusively LITA and RA for complete revascularization in elective, as well as, non-elective surgeries. The clinical evolution was excellent with $97 \%$ of patients being asymptomatic and free from re-intervention. This technique will probably have long-term benefits because RA endurance might prove similar to that of LITA.

In our study, the LITA-LADA had the same high patency rates in elective and non-elective groups found in the literature, proving to be the gold standard procedure of CABG surgery.

In a small number of patients, the LITA-Diagonal-LADA sequential anastomosis was used, resulting in an overall graft patency rate that was lower than the standard LITA-LADA. Actually, LITA-Diagonal-LADA in the elective group had a lower patency rate than in the non-elective group. The difference was significant, but the number of grafts was low. Further studies should clarify if the problem lies with the sequential procedure and/or the elective/non-elective scenarios. Either way, a word of caution regarding the LITA-DiagonalLADA procedure is in order because it is a technically chal- 
lenging sequential anastomosis. Another consideration is the LITA, which passes through the Diagonal branch, has to be a longer graft in order to reach the LADA, resulting in a terminal portion of the LITA graft with a smaller caliber. The association of these factors with competitive native flow through both the Diagonal and LADA may have some impact in sequential LITA graft patency leading to graft failure. In spite of these differences, both patients with sequential LITA occlusion were asymptomatic and their myocardial stress scintillography was negative for ischemia. A future repeat of image control of these same patients will be interesting to determine whether the LITA will, or not, become patent with the progression of atherosclerosis in the native vessels.

There are some limitations to the present study that must be recognized. First, the present study was not performed with a control group receiving a saphenous vein that would be used to compare to the radial artery. Second, this study had a relatively small sample size, which might be insufficient to determine significant differences between target vessel patency rates. Third, we had 5 late deaths and a $29 \%$ loss of surviving patients, thus this combination might have overestimated the patency rates by selecting for patients who survived and were available for the study. Fourth, the se- lection of patients for MDCT was retrospective and not randomized; however, data analysis for the MDCT was done by a blinded observer.

MDCT must be considered as a choice for follow-up of CABG in comparison with selective coronary angiography because it is a noninvasive procedure without hospitalization. It may lead to other diagnostic findings such as pericardial and pleural effusions, chest neoplasm in the early stage, and eventually a precise mapping of the vessels for a redo CABG. In fact, the 64-Slice Computer Tomography generation has great image definition, even though it still can not be considered the gold standard for coronary artery disease. Future advances in MDCT technology are likely to challenge selective coronary angiography. This may change the relationship between diagnosis and treatment as the clinician will be able to indicate MDCT and decide on a procedural course without interference by other physicians.

\section{CONCLUSION}

The RA can be used in both elective and non-elective patients with excellent results.

\section{RESUMO}

Rocha-e-Silva R, S.G. Santos T, Rochite CE, Rocha-Filho JA, Mansur AP, Fabri Jr. J, Ramos RB, Dallan LAO, Stolf NAG. Enxertos de artéria radial eletivos vs emergência: Comparando resultados em seguimento a médio prazo. Clinics. 2007; 62(6):725-30.

INTRODUÇÃO: A anastomose da artéria torácica interna esquerda com a artéria descendente anterior (ATIE-DA) se tornou parte fundamental da cirurgia de revascularização do miocárdio (RM). Esta técnica levou ao aumento de utilização de outros enxertos arteriais, entre os quais, a artéria radial (AR) é muito usasa. Na literatura há controvérsia se a AR pode ser usada em pacientes em RM de emergência.

MÉTODOS: 47 pacientes com lesões críticas ( $270 \%)$ em todas as artérias alvo foram submetidos à RM com ATIE e a AR entre 1996 e 2003. Os pacientes foram agrupados em eletivos (23 pacientes) e não eletivos (24 pacientes) sendo similares para número de enxertos de ATIE e AR por paciente. Dos 47 pacientes, 5 morreram de complicações não cardíacas e 12 não estavam disponíveis. Portanto, 30 pacientes (71\% dos sobreviventes) foram estudados com tomografia computadorizada. Um total de 36 ATIE e 64 AR foram analisadas. 
RESULTADOS: a perviabilidade da AR nos grupos eletivo e não eletivo foram respectivamente $82 \%$ (31/38) e $85 \%$ (22/ 26) $(\mathrm{p}=0,75)$. A AR teve perviabilidade semelhante para todas as artérias alvo variando de $73 \%$ a $100 \%$. Apenas um paciente foi submetido à nova RM e 29 (97\%) estão livres de angina ou nova re-intervenção. ATIE-DA teve perviabilidade de $92 \%$ $(11 / 12)$ e $100 \%$ (10/10) respectivamente nos grupos eletivo e não-eletivo $(\mathrm{p}=0,37)$. ATIE-Diagonal-DA seqüencial obteve perviabilidade de $50 \%$ (03/06) no grupo eletivo que foi significativamente menor que a perviabilidade de $100 \%$ (08/ 08) do não-eletivo $(\mathrm{p}=0,02)$.

CONCLUSÃO: A AR pode ser utilizada nos pacientes eletivos e não eletivos com excelentes resultados.

UNITERMOS: Revascularização do miocárdio. Enxertos arteriais. Tomografia computadorizada. Cirurgia. Emergência. Imagem de artéria coronária. Doença isquêmica do coração.

\section{REFERENCES}

1. Zeff RH, Kongtahworn C, Iannone LA, et al. Internal mammary artery versus saphenous vein graft to the left anterior descending coronary artery prospective randomized study with 10 year follow up. Ann Thorac Surg $1988 ; 45: 451-4$

2. Acar C, Jebara VA, Portoghese M, et al. Revival of the radial artery for coronary artery bypass grafting. Ann Thorac Surg 1992;54:652-60.

3. Sundt TM 3rd, Barner HB, Camillo CJ, Gay WA Jr. Total arterial revascularization with an internal thoracic artery and radial artery $\mathrm{T}$ graft. Ann Thorac Surg 1999;68:399-405.

4. Royse AG, Royse CF, Tatoulis J, et al. Postoperative radial artery angiography for coronary artery bypass surgery. Eur J Cardiothorac Surg 2000;17:294-304

5. Possati G, Gaudino M, Alessandrini F, et al. Midterm clinical and angiographic results of radial artery grafts used for myocardial revascularization. J Thorac Cardiovasc Surg 1998;116:1015-21.

6. Bhan A, Gupta V, Choudhary SK, et al. Radial artery in CABG: could the early results be comparable to internal mammary artery graft? Ann Thorac Surg 1999;67:1631-6.

7. Fremes SE, Christakis GT, Del Rizzo DF, Musiani A, Mallidi H, Goldman BS. The technique of radial artery bypass grafting and early clinical results. J Card Surg 1995;10:537-544.

8. Calafiore AM, Teodori G, Di Giammarco G, et al. Coronary revascularization with the radial artery: new interest for an old conduit. J Card Surg 1995;10:140-6.

9. Khot UN, Friedman DT, Pettersson G, Smedira NG, Li J, Ellis SG. Radial Artery Bypass Grafts Have an Increased Occurrence of Angiographically Severe Stenosis and Occlusion Compared With Left Internal Mammary Arteries and Saphenous Vein Grafts. Circulation 2004;109:2086-2091.

10. Di Lazzaro D, Ragni T, Di Manici G, et al. Noninvasive midterm followup of radial artery bypass grafts with 16-slice computed tomography. Ann Thorac Surg. 2006;82:44-50.

11. Oz BS, Iyem H, Akay HT, et al. Mid-term angiographic comparison of sequential and individual anastomosis techniques for diagonal artery. $\mathrm{J}$ Card Surg. 2006;21:471-4.

12. Dallan LA, Oliveira SA, Lisboa LA, et al. Complete myocardial revascularization with exclusive use of arterial grafts. Rev Bras Cir Cardiovasc. 1998;13:187-93.
13. Legare JF, Buth KJ, Sullivan JA, Hirsch GM. Composite arterial grafts versus conventional grafting for coronary artery bypass grafting. J Thorac Cardiovasc Surg. 2004;127:160-6.

14. Tatoulis J, Buxton BF, Fuller JA. Patencies of 2127 arterial to coronary conduits over 15 years. Ann Thorac Surg. 2004;77:93-101.

15. Gaudino M, Alessandrini F, Pragliola C, et al. Effect of target artery location and severity of stenosis on mid-term patency of aorta-anastomosed vs. internal thoracic artery-anastomosed radial artery grafts. Eur J Cardiothorac Surg. 2004;25:424-8.

16. Zacharias A, Habib RH, Schwann TA, Riordan CJ, Durham SJ, Shah A. Improved survival with radial artery versus vein conduits in coronary bypass surgery with left internal thoracic artery to left anterior descending artery grafting. Circulation. 2004 30;109:1489-96.

17. Kamata S. Emergency and subemergency coronary artery bypass graft: active use of arterial grafts. Kyobu Geka. 1999;52(8 Suppl):693-6.

18. Hirotani T, Kameda T, Kumamoto T, Shirota S, Yamano M. Should arterial grafts be used for urgent coronary artery bypass surgery? Kyobu Geka. 2000;53:69-73.

19. Chowdhry TM, Loubani M, Galinanes M. Mid-term results of radial and mammary arteries as the conduits of choice for complete arterial revascularization in elective and nonelective coronary bypass surgery. J Card Surg. 2005;20:530-6.

20. Hayashi S, Sasaki M, Kawamoto J. Urgent coronary artery bypass surgery by only arterial graft for acute myocardial infarction. Nippon Kyobu Geka Gakkai Zasshi. 1997 Jul;45:935-9.

21. Nishida H, Tomizawa Y, Endo M, Koyanagi H. Complete arterial revascularization in emergency CABG. Kyobu Geka. 1999 Jul;52(8 Suppl):688-92.

22. Rocha-e-Silva R, Mansur AP, Fabri Junior J, et al. Coronary revascularization with left internal thoracic artery and radial artery. Comparison of short-term clinical evolution between elective and emergency surgery. Clinics. 2005 Jun;60:227-32.

23. Miana LA, Lima DS, Whitaker JF, Passos PHC, Loures JBP, Miana AA Immediate results of right internal thoracic artery and radial artery as the second arterial graft in myocardial revascularization. Rev Bras Cir Cardiovasc 2007;22: 60-67. 